\title{
Metáforas de la higiene y la iluminación en la ciudad poetizada bajo el Chile autoritario
}

\author{
Metaphors of hygiene and lighten of the city poetized \\ under the authoritarian Chile
}

\author{
Magda SepúlvedA* \\ Pontificia Universidad Católica de Chile. Chile \\ msepulvu@uc.cl
}

\section{RESUMEN}

La ciudad representada en la poesía y el video arte editados en Chile bajo la dictadura exhiben coincidencias, articulándose los núcleos simbólicos de la higienización y la iluminación. A partir de estas convergencias retóricas es posible trazar rutas de lectura entre los poemarios de Raúl Zurita, Alexis Figueroa, Tomás Harris y Carmen Berenguer y los videos realizados por artistas visuales de la promoción emergente de la época, entre éstos, Eugenio Dittborn, Magaly Meneses, Diamela Eltit y Lotty Rosenfeld.

Palabras claves: Poesía chilena, ciudad, Zurita, video arte, dictadura, Eltit.

\section{ABSTRACT}

The city represented in the poetry y art video edited in Chile under the period of the military dictatorship exhibit similarities which are expressed in the symbolic cores of hygienization and lighten. On the basis of these rhetorical convergences, it is possible to map out courses of reading among the poems written by Raúl Zurita, Alexis Figueroa, Tomas Harris and Carmen Berenguer and the videos made by visual artists belonging to the emergent group from the period, such as Eugenio Dittborn, Magaly Meneses, Diamela Eltit and Lotty Rosenfeld.

Keywords: Chilean poetry, city, Zurita, art video, dictatorship, Eltit.

Recibido: 08-10-2008 Aceptado: 28-10-2008

*Este trabajo forma parte del proyecto Fondecyt No 1085255 titulado "Representaciones de la ciudad en la poesía chilena posgolpe (1973-2006)”, del cual soy investigadora responsable. 
R ecuerdo ese día, estaba en una clase de enseñanza básica. La directora Lirrumpió para informarnos que debíamos regresar a nuestras casas: los locos se habían escapado del manicomio. Era un martes 11 de septiembre de 1973. Los días siguientes fui observando desde mi ventana cómo militares limpiaban la propaganda política de los muros, mientras los vecinos hacían funcionar el incinerador del edificio a toda prisa. Ellos también limpiaban sus casas. Cuando retornamos a clase, nos revisaban las uñas y el cabello; y a los chicos el largo del pelo, que no debía exceder el cuello de sus camisas. Mis años de enseñanza básica transcurrieron durante la dictadura militar chilena (1973-1989), por ello, deduzco, desde este presente, nos insistían tanto en la limpieza. A la distancia, pienso que la metáfora de la higienización elaborada por el autoritarismo fue una forma de violencia epistémica ${ }^{1}$ que permitió llevar a cabo un programa consistente en erradicar lo sucio y leo ese 'erradicar' justamente como un problema territorial. Un conjunto significativo de textos poéticos y videos del período trabajan alrededor de simbolizaciones sobre lavado o ensuciado. El video, cuyo auge coincidió con la dictadura militar ${ }^{2}$, fue empleado por algunos de los intelectuales que formaron el CADA (Colectivo de Acciones de Arte), entre quienes estaban Raúl Zurita, Diamela Eltit, Lotty Rosenfeld y Eugenio Dittborn. Por tanto, algunas consonancias trópicas entre poesía y video, que pretendo demostrar aquí, no son meras casualidades. Pero estas isotopías no fueron propiedad exclusiva del CADA, funcionaron de diversas maneras en otros poetas y videístas, porque el tema de la higiene estaba puesto por la dictadura. Cabe preguntarse entonces si las relaciones entre video y poesía están más cerca de un diálogo afirmativo o polémico con el discurso hegemónico de la belleza de una ciudad limpia.

\section{LEJOS DE LA CIUDAD LIMPIA, EL DESIERTO}

Para acercarme a la cuestión planteada comenzaré por establecer un cruce entre Purgatorio (1979) de Zurita y el video-arte ${ }^{3}$ La mancha de aceite de Dittborn

${ }^{1}$ El concepto de 'violencia epistémica' fue empleado por Gayatri Spivak en “¿Can the subaltern speak?” (1988) para referirse a la negación de los significados dados y practicados en una comunidad por parte de los grupos colonizadores. Siguiendo esta noción, es posible afirmar que asociar la barba y el pantalón ancho con lo sucio, fue un acto donde se le negó al otro su capacidad de representarse.

${ }^{2}$ Los primeros videos-arte producidos en Chile corresponden a los efectuados por Juan Downey (1940-1993) para la exposición "El juego cibernético" (1968), que realizó en conjunto con el artista surcoreano Nam June Paik, y "Anaconda” (1975), en este último se presentaba el mapa de Chile y sobre él una serpiente.

${ }^{3}$ Sigo a Nelly Richard en su definición de video arte. No es el video utilizado como registro o 
(1981). Ya se imaginarán ustedes que me interesa examinar el núcleo simbólico de 'la mancha' en ambos autores. Zurita traza dos escenarios fundamentales: el baño y el desierto. En el baño, el sujeto zuritiano sufre una pulsión de limpieza, con la cual intenta eliminar esa mancha que ha caído sobre él. Pero, ¿̇a qué se debe esta mancha? La respuesta está alrededor del descalificativo "perro" (16) que recibe este protagonista. Sobre 'perro', la RAE dice: "Fig. Nombre que las gentes de ciertas religiones daban a las otras por afrenta y desprecio". La ofensa establece un acto, la separación de un sujeto de su grupo. Es posible entonces leer una línea de continuidad entre el insulto y la acción de limpieza que el sujeto ejecuta en el baño. La higienización lo transforma en otro ser, ahora es alguien que puede "volver después de su propio" (25) origen. El sujeto sucio se borra y aparece uno nuevo que se autoengendra. La transformación incluye un cambio de sexualidad y una aparición en la ciudadanía del espectáculo: "Todo maquillado contra los vidrios / me llamé esta iluminada dime que no / el Súper Estrella de Chile" (14). Para participar de la ciudad, el sujeto acepta, mediante un proceso de limpieza, someterse al Nombre del Padre ${ }^{4}$. El poeta Jorge Etcheverry ${ }^{5}$ reproduce satíricamente ese Nombre del Padre en uno de sus textos: "Lo que pasa es que nadie nos entiende / Hemos limpiado a Chile del marxismo / Lo que pasa es que nadie nos entiende" (1986: 16). Sin embargo, el poemario de Zurita va más allá de la fase de higienización que, según mi opinión, constituye en él sólo una primera etapa.

En un segundo estadio, el sujeto se desplaza hacia otro espacio, el desierto. Allí, el personaje de Zurita traspasa la instancia de la amenaza de castración $\mathrm{y}$ hace fracasar el proceso de edipización ${ }^{6}$, pues decide aceptarse como manchado. Tal como Kafka deviene en cucaracha para escapar de hacerse cargo

soporte de memoria, sino en un uso que va "contra la transparencia representativa de la historia, (...) el video-arte designaría aquellas obras en las que los recursos de construcción se exhiben a sí mismos como artificios" (1986: 3). Richard menciona entre los videístas del período (1979-1980) a Dittborn, Eltit, Rosenfeld, Leppe, Meneses, Jaar, Codocedo, Fariña, Flores, Altamirano y Forch.

${ }^{4}$ El Nombre del Padre es, en la escuela lacaniana, el "no del padre", es decir la voz que actúa para subrayar la función prohibitiva, la ley (Evans, 1997: 138).

${ }^{5}$ Etcheverry desnaturaliza el discurso pronunciado por Sergio Diez, quien en calidad de embajador del gobierno de Pinochet ante la ONU declaró que las Organizaciones de Derechos humanos en Chile eran malintencionadas, puesto que las personas que reporteaban como desaparecidos no existían o se encontraban fuera del país.

${ }^{6}$ Siguiendo a Deleuze y Guattari (2002), entiendo por proceso de edipización escuchar la amenaza de castración, proveniente del padre o de ley, y comportarse como estas instituciones lo exigen. Por el contrario, el fracaso del proceso de edipización no consiste en escuchar la prohibición paterna y desobedecerla; sino en no oírla, lo que se traduce en ver otros caminos, otras madrigueras, allí donde el padre sólo vio un camino y una encrucijada. Por ello, leo en este irse al desierto de Zurita y Dittborn un fracaso del proceso de edipización, una inauguración del mundo esquizo como posibilidad habitable. 
en términos económicos de su familia; el protagonista de Purtagorio opta por el devenir vaca, una metonimia que lo liga hacia un pasado, al subsidio de la leche para los sectores desposeídos, medida que formaba parte del gobierno de la Unidad Popular. En esa nueva condición, él con "Sus manchas finalmente / van a perderse en otros mundos" (49), que son llamados landa, jota, ypsilón, adoptando el poemario un lenguaje matemático y entrando el sujeto en un universo algebraico y alucinado. Estos otros universos configuran un lugar fuera de la ciudad, un sitio inscrito en el desierto donde el orden humano no alcanza a llegar ${ }^{7}$. En estos espacios otros, la mancha pasa a ser una condición de la cual el sujeto no intentará limpiarse. El personaje ha producido su desterritorialización al huir del Edipo. Zurita ha transitado, desde el intento de borrar la mancha como condición para vivir en la ciudad higienizada, hasta la aceptación de la mancha entendida como característica del que habita en un espacio sin reglas ni divisiones, donde la convivencia de lo imposible es el ejercicio. Ese lugar es el desierto.

El tema de salir de la ciudad tiene una línea de consonancia con el registro en video de la performance realizada por Dittborn en el Desierto de Tarapacá (1980) que se incluye en la cinta Historia de la fisica (1983). La secuencia muestra al artista dando vuelta un tambor de aceite quemado en la aridez del desierto, pero el líquido no escurre lo suficiente y entonces Dittborn debe desparramar con sus manos el aceite desde el tambor hacia la tierra árida. Se genera entonces la mancha en el Desierto. En su libro Estrategias y proyecciones de la plástica nacional sobre la década del ochenta, el artista expresa: "lugar común es eyacular, menstruar, salivar, supurar, llorar y sudar" (1979: s/n), es decir, liga la mancha a los líquidos del cuerpo, lo que conectaré con el deseo de derrame, deseo de incontinencia en un país represivo. Mi lectura apunta a las connotaciones que aparecen al relacionar mancha, derrame y fluidos. Dittborn ha dicho: manchas seminales, manchas de sangre y manchas de sudor. Dittborm es el que hace ver la mancha, el que sitúa sus manos como instrumento del derrame, del volcamiento del adentro hacia el afuera. Dittborn coincide con Zurita en buscar el Desierto, en sacarse el Edipo, en huir de la ciudad de la higiene. En ambos textos, el desierto se densifica simbólicamente, representa lo opuesto a la ciudad. Si en la ciudad lo que prima es la limpieza, la homogeneidad, el límite, el encierro y la ubicación de manicomios, basurales y cementerios en el extrarradio; en el desierto, por el contrario, los cadáveres y todo desecho

${ }^{7}$ Ese lugar otro hacia donde va Zurita puede leerse como la psiquis del loco. Rodrigo Cánovas propone que el manicomio es el lugar de partida, "Purgatorio (evoca la dictadura) desde la metáfora del Sanatorio, entendiendo éste como una cárcel donde se aniquila física y mentalmente nuestros valores, nuestras ideas y nuestros sueños" (1986: 84). 
son visibles y se conservan en un espacio infinito, sin fronteras, donde todo se desdibuja y son puras manchas.

\section{EN LA CIUDAD MANCHADA, SER EL SÚPER ESTRELLA DE CHILE}

Sin embargo, la alternativa de huir de la ciudad es un imposible en otros textos. Por ejemplo, para Alexis Figueroa los dos espacios posibles son el baño y el escenario teatral. Alexis Figueroa, en su libro de poemas Vírgenes del Sol Inn Cabaret (1986), Premio Casa de las Américas, liga la mancha al origen del sujeto mestizo. De acuerdo al poeta, el origen mancillado produce un deseo de anulación de la etnicidad, que se refuerza con la adscripción a un imaginario donde las identidades mestizas no son visibles, lo que genera el deseo de imitar la representación ligada a las pinturas europeas y formatos de los mass media. Figueroa centra su atención en un grupo de mujeres que tratan de imitar, en sus cuerpos, las pinturas italianas renacentistas: "las muchachas se retocan afirmadas en el water, acodadas / en el lavamanos, / (...) /. Algunas juegan a ser modelos de Veermer, Rubens, / Boticelli” (20). Figueroa y Zurita coinciden en poetizar el baño como el espacio donde se realiza la limpieza de lo que se considera feo y sucio. Desde mi punto de vista, la importancia dada al baño tiene que ver con la higienización fascista que consideró a todo rebelde un sucio, un manchado. Pienso en una pintura de Gonzalo Díaz de la misma época donde trabaja, en un estilo pop, la imagen de la dueña de casa de las cajas de Klenzo. El título de la serie de Díaz, "Kosmética” (1982), parece dar un guiño al poemario de Figueroa, en el sentido de que conceptualiza la limpieza como una cosmética, vale decir, cierta forma de maquillaje es un intento de ocultar la piel y entrar en las estéticas del disciplinamiento. Por ello, estos poetas, Zurita y Figueroa, focalizan el baño como el lugar de la cosmética, el espacio donde el sujeto elimina lo que considera su excrescencia y se aliena. Sin embargo, Zurita y Figueroa se diferencian; en Zurita, el sujeto manchado deja atrás su deseo de limpieza y se acepta, mientras que en Figueroa, profundiza cada vez más en el extravío, modificándose hasta convertirse en el súper estrella de Chile.

Aquellos que no pueden huir al desierto, deben aprender otra forma de ciudadanía: ser el súper estrella de Chile, esto es, entender la ciudadanía como un espectáculo. El súper estrella de Chile concibe el espacio público como un teatro, una comedia de apariencias, pero con un ingrediente monstruoso, la violencia hacia sí mismo. Esto se debe a que la participación en el baile de máscaras auspiciado por la dictadura requiere un proceso de higiene: una vez que el sujeto acepta limpiarse está también dispuesto a entrar en el nuevo 
universo de los intercambios comunicacionales. Intercambios que se realizan bajo la luz de los medios, donde el súper estrella sólo puede transitar como mercancía. De esta forma, el habitar se torna una variante del ejercicio de la prostitución. Por ejemplo, Zurita trabaja la idea de que la nueva ciudadanía se ejerce desde la creación de una imagen, condición que liga a la feminidad: "me llamo Raquel / estoy en el oficio / desde hace varios / años" (11). Figueroa sigue en esta línea, pero agrega que la prostitución del yo ocurre en la medida que ingresa a la ciudad regida por los medios. Por ello, el lenguaje de sus poemas imita la repetición propia de la retórica televisiva. Si en la televisión vemos una y otra vez la misma imagen, en Figueroa escuchamos una y otra vez el estribillo que nos invita a entrar en el espectáculo: "Welcome to the tv, / welcome to the machine" (1986: 12).

El sujeto deseará entrar en la máquina cuyo producto es la exhibición de 'yo'. La urbe es el lugar donde el sujeto debe mostrar cuánto se traiciona a sí mismo. Leo entonces la ciudad como un museo perverso, donde se exhiben los que tienen una versión alterada de la ley del padre, los que son siempre sus hijos, dispuestos a acatar las órdenes de quien los castra. Las poetas reflexionaron sobre esta ciudadanía exhibicionista, desde su condición de género. Por ejemplo, Carmen Berenguer enfatiza la violencia que implica salir a escena. En Huellas de siglo (1986), Berenguer crea una secuencia desde el lavado hasta la vitrina publicitaria. Para ella, el proceso de 'limpieza política' tiene que ver con cocinar:

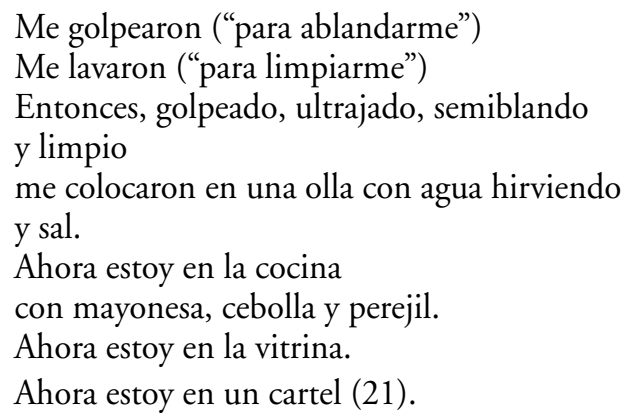

En este poema los procedimientos de tortura se homologan a los pasos de una receta de cocina. Así como la mujer cocinera golpea, limpia y transforma objetos en alimentos, de la misma forma el torturador golpea, limpia y transforma cuerpos en ciudadanos. En el caso de la dictadura la operación de pasar de lo crudo a lo cocido no persigue producir un ciudadano moderno, sino un ciudadano que disfrute estar "en la vitrina".

Veo coincidencias entre Berenguer y la videísta Magali Meneses, quien 
simboliza también la unión entre limpieza, comida y tortura, en su video La comida (1983). La cinta muestra a Meneses cortando unos piures con un cuchillo, luego los saca de su concha, los pone en un plato y los cuece con limón, botando los excedentes. Posteriormente, Meneses y Sybil Brintrup se comen los piures, mientras toda la escena es repetida en un monitor de televisión. Destaco este hecho del televisor puesto en escena, puesto que veo en ello la conciencia de exhibición que rodea cierto registro de los textos producidos por mujeres. Nelly Richard interpreta esta cinta "como teatralización de una cotidianidad femenina" (1986: 6). Comparto y agrego la connotación política de esa teatralización: cortar la pieza de piure como alegoría del acto de separar a una comunidad y luego despojar a cada uno de sus individuos de su ambiente para que así puedan ser 'cocidos' y posteriormente exhibidos en el monitor. Estas artistas sitúan la violencia en la ausencia de lo privado, la comida realizada por ellas está hecha para ser mostrada. La violencia necesaria para entrar al espectáculo es dar vuelta la costura, es decir, la transformación de todo interior en exterior. Hasta aquí tenemos dos requisitos de esta nueva ciudadanía: limpieza y violencia.

Otra de las mujeres que trabaja la ciudadanía como espectáculo es Diamela Eltit, en cuyos videos veo una relación compleja con este tema. La unión entre espectáculo y lavado se aprecia en uno de sus videos titulado Zona de Dolor I (1980), donde la escritora lee pasajes de Lumpérica y luego lava la acera aledaña al prostíbulo. Se suma a esto la proyección del rostro de Eltit sobre una de las murallas colindantes al burdel. Para el evento, la calle fue iluminada con un foco potente, bajo el concepto de mostrar las zonas oscurecidas por la sociedad. ¿Qué significados adquiere aquí el lavado de la calle? Lavar es eliminar la excrescencia, borrar los orines de la noche arrabalera anterior. Llegamos aquí a la misma encrucijada entre mancha, limpieza y derrame de fluidos. Sin embargo, Eltit opta por limpiar la mancha. ¿Busca higienizar la urbe? Por momentos, Eltit se me asemeja al artista naturalista ${ }^{8}$ en su deseo de iluminar y limpiar los márgenes oscuros de la ciudad. En otros momentos, la veo interesada en mostrar quién ejecuta los procedimientos de limpieza; tal como Berenguer destaca la cocinera, Eltit pone en escena a la lavandera ( $y$ todo lo que esta figura nos recuerda, desde el cuadro "El huaso y la lavandera" de Rugendas, como posición de subordinación). El video es ambiguo entre el canon naturalista sobre iluminar las zonas oscuras de la ciudad y el deseo vanguardista de colocarse en el centro de la imagen y hablar. De estas tensiones, la más interesante, para mí, es la

${ }^{8}$ La relación entre higiene, unión nacional y escritura naturalista es analizada en el subcapítulo "Higienismo y vigilancia" del libro Ficciones somáticas: Naturalismo, nacionalismo y políticas médicas del cuerpo (Argentina 1880-1910) de Gabriela Nouzellies (2000: 37-45). 
acción de situarse en un lugar marginal ${ }^{9}$ de la ciudad versus el gesto publicitario de proyectar su rostro en la muralla.

Examinemos este gesto de Eltit de inscribir su rostro y su cuerpo en la ciudad. En la cinta, está instalada en el burdel, se torna otra prostituta más, inmediatamente pensamos en Baudelaire, ya sabemos, todo artista moderno se encuentra en una situación prostibularia, él mismo es su propia mercancía que pone en venta. La nueva galería de arte es el prostíbulo. ¿Qué agrega Eltit? Nada menos que el nuevo soporte por el que pasará esa transacción, la imagen. Eltit comprende que los vínculos sociales en la ciudad dictatorial están atravesados por los medios de comunicación que transmiten imágenes, principalmente, la televisión; lo cual explica que estos artistas estén recurriendo al video. Entonces sitúo como de máxima importancia la secuencia de la proyección de su rostro, ella como aviso publicitario de sí misma. Ella iluminada iluminándose. Recuerdo la extraña dedicatoria de Zurita en la edición original de Purgatorio: "A Diamela Eltit, la santísima Trinidad y la pornografía". Los nuevos ciudadanos han recibido la luz del neón publicitario y del foco vigilante. Han aprendido a ejercer la ciudadanía como "seductriz" (Figueroa, 1986: 30). Para Berenguer, la nueva metrópolis es indudablemente ramera: "Carente de decencia, marginal, fantoche / (...) / Pobre dama, empielada ramera" (1986: 17). La ciudadanía exhibicionista sólo es posible en un régimen que nos naturalizó que el espacio público era un simulacro.

\section{LUCES ESPECTRALES, ATRAVESAR EL BALDÍO}

El burdel es aludido también en "Zonas de peligro" de Tomás Harris (1996), quien coincide con Eltit en la idea de iluminar la zona oscura de la ciudad, los barrios prostibularios, esta vez de la ciudad de Concepción. No es vacuo que ambos textos se llamen "zonas", aludiendo al terreno sobre el cual pesa una restricción de entrada. Si bien comparten este interés por los sitios del margen al orden visible de la ciudad, Harris enfatiza las condiciones históricas de generación de ese espacio y en ello está más cerca de Figueroa. Para Harris, el territorio devastado no es sólo consecuencia del gobierno militar, sino de las políticas de erradicación iniciadas desde la Colonia, cuyo efecto ha sido la generación de este espacio habitado por espectros, cuerpos asesinados o desaparecidos. Los personajes del peladero son mendigos, prostitutas y travestis,

${ }^{9}$ La tensión que presenta el video Zona de dolor de Eltit respecto de la espectacularización de la ciudadanía, no se ve en su narrativa; por ejemplo, en Lumpérica, la mendiga decide sustraerse al influjo publicitario luminoso de la ciudad. 
vale decir, cuerpos rechazados y a la vez producidos por el sistema que los arroja a ese lugar. El baldío es entonces una cárcel donde están recluidos los apestados, "el / baldío de Orompello te inventa una cár- / cel oculta al otro extremo de La Concep / ción" (49). Las murallas del peladero son los letreros de neón: "y los escasos letreros de neón ocultan su única / identidad: / CAMPOS DE EXTERMINIO” (29). El letrero luminoso o el mercado funcionan igual que la dictadura, dividiendo a los habitantes. El baldío es habitado por los espectros y el centro es ocupado por los golems o monstruos creados en un intento de imitar la publicidad. En los dos espacios, la realidad se desdibuja, sucede ese extravío de los sentidos que Oscar Galindo (2002) lee perspicazmente como un tópico barroco y la vida como teatro (otro tópico barroco), entrada que comparto y a la cual agrego el antecedente de la dictadura como provocadora de esta confusión realidad/irrealidad ${ }^{10}$ que equivale a la pérdida de ciudad en los dos escenarios. Además la alucinación es realzada por las diversas voces que emplea Harris, hablas que no se sabe de dónde provienen y que se articulan por medio de montajes, recurso émulo del cine y de los medios de comunicación masivos. La iconización de la cultura correspondió a una estrategia de la dictadura, donde la tecnología de las comunicaciones fue un vehículo de disciplinamiento; la importancia dada por el gobierno de Pinochet a la TV fue expresada por el ministro del Trabajo, José Piñera, en 1980: "De cada siete chilenos, uno tendrá automóvil; de cada cinco, uno tendrá televisor, y de cada siete, uno tendrá teléfono" (El Mercurio, 28 de agosto, 1980). El poemario se hace cargo de esta asociación entre dictadura y sociedad del espectáculo. Por ello, la ciudad chilena posgolpe es sólo un simulacro de ciudad y de civilidad.

Coincidiendo con Harris en la noción de muertos sin sepultura, Lotty Rosenfeld efectúa la instalación Una milla de cruces sobre el pavimento (1979), performance ${ }^{11}$ registrada en video. Ahora la frontera ya no es un letrero de neón, sino una vía de circulación automotriz en ambas direcciones. El trabajo consistió en añadir, a las líneas verticales de una de las vías de Manquehue, un lugar del

${ }^{10} \mathrm{La}$ urbe dictatorial como ciudad producida por los medios es un recurso que han trabajado varios narradores, Diamela Eltit en Lumpérica (1983) y Roberto Bolaño en Estrella Distante (1996), entre otros. En este último libro la relación entre medios y dictadura se focaliza en un escritor que registraba en fotos sus ejercicios torturadores: "en algunas de las fotos reconoció a las hermanas Garmendia y a otros desaparecidos. La mayoría eran mujeres. El escenario de fotos casi no variaba de una a otra por lo que se deduce que es el mismo lugar. Las mujeres parecen maniquíes desmembrados, destrozados" (97).

${ }^{11}$ Diamela Eltit rescata el carácter preformativo de esta acción de arte: "La salida del marco, es la salida del muro que lo contiene. A ras del suelo, sin techo, ni puerta, se extiende, planteando una contradicción, por decir lo menos, con las otras formas de arte. Contraviniendo interroga a la pintura/ la galería/ el museo que por un instante se petrifican óseos en su institucionalidad inerte" (1986: 14). 
extrarradio de Santiago de los '70, un género blanco horizontal. La artista y el colectivo CADA se presentó por segunda vez en avenida Manquehue, pero ahora para proyectar el video que habían filmado. Me parece que Rosenfeld lleva la representación de la mujer a la calle, en un oficio que tradicionalmente no es desempeñado por mujeres, poner señales de tránsito. Luego, al exhibir el video en el mismo lugar, insiste en mostrar a la mujer en la calle, lo importante es su condición, no su rostro, por ello no hay secuencias de primer plano, sino planos generales donde se representa ella de cuerpo entero. Rosenfeld sale de la cocina y del prostíbulo, lugares encomendados a los ejercicios femeninos y presenta su cuerpo en la calle. Esta mujer es la mujer que se toma la calle, vulnerando las circulaciones definidas para los trayectos femeninos. Richard ve en la venda que "al cruzar la marca, la artista transforma el signo - en un signo +" (2008: 348), creando así plurales de significación o por tanto, nuevos movimientos urbanos. Pienso que este quiebre en los horizontes rígidos se logra gracias a la inclusión de otras subjetividades, entre ellas las de género, que son expresadas a través de la presencia de la artista en la calle y por medio de la colocación de "género (producto blando/ manufacturado) sobre el duro pavimento gris" (Brito y Eltit, 1980: 35). El género se torna entonces en un aparato desarticulador del poder que reglamenta la experiencia diaria.

Rosenfeld hace la suma de los caídos, la venda en el pavimento traza cruces, así ella efectúa el tributo simbólico a los muertos, indica que el camino y la ciudad son la topografía de la muerte. Tras su intervención, las cruces blancas connotan la ciudad como un cementerio. Entonces hay coincidencia entre la ciudad espectral de Harris y la ciudad cementerio de Rosenfeld. Sólo que la salida de Rosenfeld es positiva, frente a los cuerpos muertos y desaparecidos, ella hace emerger su cuerpo iluminado por la luz del día.

Las cruces de Rosenfeld convergen con el trabajo de otro integrante del CADA, Gonzalo Muñoz, quien en su poemario Este (1983) trabaja al igual que Lotty Rosenfeld el tema de la cruz. Gonzalo Muñoz opta, en su texto, por una cruz girada, una X que le permite referencias múltiples, en algunas de las cuales coincide con Rosenfeld. Un punto de similitud es considerar a la ciudad un cementerio: "una matanza sin fin que marcó (X) la necesidad de otros relatos en este continente asolado de caídos, carentes de una doble historia que ha dado voz a los muertos: porque ellos vagan por los caminos" (75). En esta cita podemos observar que la X funciona como la tachadura efectuada sobre los asesinados, borrándoles incluso el nombre, por eso la voz intenta una primera recuperación al llamar al cadáver "es éste, es ESTE, es E.S.T.E" (11). Estos borrados serán multiplicados, otra $\mathrm{X}$, según Gonzalo Muñoz: "los que sin nombre atraviesan ya multiplicados toda la historia” (1983: 60). La incógnita 
y el enigma tendrían, siguiendo a Pablo Oyarzún, un doblez en la forma hermética de escritura que posee el poemario: "lo no-dicho (...), el enigma (...) como escena interrumpida" (2003: 206). En Este, la cruz indica el cuerpo que cae como NN, incógnito y desconocido, pero no perdido para la historia.

Muñoz poetiza el historial de esta ciudad cementerio mediante una voz testigo que sigue a múltiples sujetos que sufren la violencia. Uno de ellos es la víctima de un proceso de ejecución política:

RATATA - TA - TA- RATATATATA

(no te dice nada más)

el cubo ahora se triza en una escena de grito - círculos concéntricos se expanden salpicando las paredes blancas - el audio sigue percibiendo al caído emisor descontrolado que en sombras áun no lo oye (10).

A través del tejido escritural del poema en prosa densificado por imágenes de agresión: perder la piel en las alambradas, cortas, figura desnuda sufriente, escena de rito y otras, el hablante logra crear un ambiente terrorífico y grotesco, donde el poeta revela que el antecedente del arte es el horror: "tomó el pincel con ambas manos / realizó dos movimientos cercenantes" (28). Aquí aparece otro de los personajes que seguirá la voz, el artista plástico, quien modifica su imagen: "se deshizo la cara con un trozo de espejo" (24). Tras la autoagresión adquiere una condición feminizada: "AUTOINMOLADA SE ABRE UNA LÍNEA SANGRANTE DE ARRIBA ABAJO" (30). Muñoz y Zurita comparten esta idea de la autoagresión como forma única de sacarse la mancha y la feminización que se adquiere con ella.

Si el "RATATA - TA- TA" no mató al sujeto, entonces lo convirtió en una "rata". En Muñoz, como en Zurita, hay conciencia de que sobrevivir a la violencia y practicar luego la autoagresión es lo que permite entrar en la ciudadanía del espectáculo, como lo hace otro de los personajes que sigue la voz:

desde que se encendieron las luces vaga abandonado, seguido de cerca por su propia sombra reflejada en los paredones al paso que entran y cortan sus miembros: columnas, grandes fotografías del paisaje, primeros planos, voces desmesuradas al fondo, grabaciones dobles (Muñoz, 1983: 7).

La iluminación es en Muñoz nefasta, está vinculada a participar del yo exhibicionista y de la ciudadanía espectacularizada. En este nuevo 'escenario', 
el yo tiene un valor de uso para el propio sujeto, lo pone a circular rápido y con gestos que buscan captar la luz del espectáculo. Para nacer al nuevo lazo social, la hipersocialización, hay que morir primero.

\section{COMENTARIOS Y CONCLUSIONES}

Las representaciones de la ciudad en un conjunto de poemarios y videos publicados durante el Chile dictatorial van desde huir de la urbe que exige la limpieza o amputación de los que piensan diferente (Dittborn y Zurita), habitarla, sabiendo que es un espectáculo perverso (Figueroa, Meneses, Eltit), que exigirá a sus moradores convertirse en los súper estrellas de Chile mediante severos procesos de higienización, a considerarla un baldío (Harris) y un cementerio (Rosenfeld, Muñoz). Dittborn y Zurita emblematizan el desierto como lugar habitable para los considerados 'desechos'. El desierto es concebido por ellos como el espacio donde reside la única posibilidad de integrar una agrupación sin jerarquía alguna, por eso mismo, tesoro y metáfora perfecta para lo que es no ciudad. Por el contrario, en Figueroa no hay desierto, porque no hay posibilidad de escapar de la ciudad y de su nuevo orden transformador. La política de espectacularización que acompaña a la dictadura es, para él, ineludible. Lo mismo sucede con Berenguer, para quien el deseo de estar en la vitrina sólo es posible después de aceptar la limpieza, o más bien recibirla como agresión, como ducha de gas. En esta línea de la ciudadanía como espectáculo, está también Magaly Meneses, quien posee total conciencia de que la vida completa del nuevo ciudadano será mediatizada, tanto porque habita en un entorno donde la comunicación se establece por imágenes como porque su experiencia será decible a través de imágenes. Para Meneses, la espectacularización llegará hasta la escena doméstica, los sujetos perderán el pudor y convertirán su vida privada en una imagen vendible. Figueroa, Berenguer y Meneses ligaron pertinentemente la pérdida de los derechos públicos al alza del valor del público.

La ciudadanía espectacularizada requiere un habitante prostibulario. El artista no escapará a esta condición. El lugar de enunciación del artista y del nuevo ciudadano será el prostíbulo. Eltit leerá la novela desde el burdel. La ciudad prostibularia es el escenario para lo transable, así es la ciudad de los negocios, una sociedad donde el deseo instalado es la visibilidad máxima, ojalá el rostro proyectado-iluminado en toda la ciudad. Singularmente, Harris también se ocupa del prostíbulo, pero, en otra dirección, pues los representa cerca de terrenos baldíos, lugares poblados por fantasmas históricos. Así como 
Harris cultiva una representación gótica de la ciudad, Rosenfeld patentiza la ciudad como cementerio, pero ella le agrega, como utopía, el tema del género. Rosenfeld 'hace calle', construye nuevas direcciones. La ciudad cobra vida cuando facilita todo tránsito, incluido, por cierto, el de las mujeres. Rosenfeld venda la calle, la sana de su circulación única, sumándole el género.

La representación de la ciudad en los textos elaborados durante la dictadura está atravesada por tres problemas: la higiene, la espectacularización y, por primera vez entra en la discusión, el género. La ciudad limpia y espectacularizada comienza a poner atención a los flujos comunicacionales más que al roce entre la multitud, por ello empieza a ser un poco una posciudad.

\section{REFERENCIAS}

Berenguer, Carmen. 1986. Huellas de siglo. Santiago: Editorial Sin Fronteras. Bolaño, Roberto. 1996. Estrella distante. Barcelona: Anagrama.

Brito, Eugenia y Diamela Eltit. 1980. Una milla de cruces sobre el pavimento. Santiago: CADA.

Cánovas, Rodrigo. 1986. Lihn, Zurita, Ictus, Radrigán: Literatura chilena y experiencia autoritaria. Santiago: FLACSO.

Deleuze, Gilles y Félix Guattari. 2002. Kafka: Por una literatura menor. Madrid: Editora Nacional.

Dittborn, Eugenio. 1979. Estrategias y proyecciones de la plástica nacional sobre la década del ochenta. Santiago: autoedición.

1983. Historia de la física. Video. Cámara de Carlos Flores. Valparaíso.

Eltit, Diamela. 1980. Zona de dolor I. Video. Cámara de Ignacio Agüero. Santiago. 1983. Lumpérica. Santiago: Ediciones del Ornitorrinco.

Etcheverry, Jorge. 1986. La calle. Santiago: Sin Fronteras.

Evans, Dylan. 1997. Diccionario introductorio de psicoanálisis lacaniano. Buenos Aires: Paidós.

Figueroa, Alexis. 1986. Virgenes del Sol Inn Cabaret. Concepción: Papeles del Andalicán/Cuadernos del Sur.

Galindo, Oscar. 2002. "Autoritarismo, enajenación y locura en la poesía chilena de fines del siglo XX. Zurita, Maquieira, Cuevas", en América Latina Hoy, 30, pp. $97-118$.

Harris, Tomás. 1996. "Zonas de peligro", en Cipango. Santiago: FCE, pp. 25-62.

Meneses, Magali. 1983. La comida. Video. Santiago.

Muñoz, Gonzalo. 1983. Este. Santiago: Imprenta Universitaria-Hernán Romero Labra.

Nouzellies, Gabriela. 2000. Ficciones somáticas: Naturalismo, nacionalismo y politicas médicas del cuerpo (Argentina 1880-1910). Rosario: Beatriz Viterbo Editora.

Oyarzún, Pablo. 2003. "Este: Señales de lectura”, en El rabo del ojo. Santiago: Universidad Arcis, pp. 199-206. 
Richard, Nelly. 2008. "Artistas mujeres bajo la dictadura militar en Chile: Fugas de identidad y disidencias de códigos", en Mujeres chilenas, fragmentos de una historia. Comp. Sonia Montecino. Santiago: Catalonia, pp. 343-352.

1986. "Contra el pensamiento-teorema: Una defensa del video-arte en Chile", en Catálogo del 6o FestivalFranco-Chileno deVideo Arte, Santiago. Disponible en: http://www.umatic.cl/images/pdf-festival6/CONTRAELPENSAMIENTO. pdf. Consulta: septiembre de 2008.

Rosenfeld, Lotty. 1979. Una milla de cruces sobre el pavimento. Video. Santiago.

Spivak, Gayatri. 1988. “¿Can the subaltern speak?”, en Marxism and the interpretation of culture. C. Nelson y L. Grossberg (Comp.) Chicago: University of Illinois Press.

Zurita, Raúl. 1993. Purgatorio. Santiago: Universitaria. 